\title{
Tutoria entre estudantes: uma proposta de trabalho que prioriza a aprendizagem
}

\author{
Lourdes Maria Bragagnolo Frison \\ Universidade Federal de Pelotas, Brasil
}

\begin{abstract}
Resumo
O propósito deste artigo é refletir sobre tutoria, entendida como uma estratégia de ensino e aprendizagem, utilizada para potencializar a aprendizagem colaborativa, realizada através da parceria entre alunos. Explorou-se, historicamente, o desenvolvimento de aspectos conceituais e estabeleceu-se como ponto de referência o estudo da tutoria na atualidade. Com esse suporte teórico, foi realizado trabalho de tutoria entre estudantes de Pedagogia de uma universidade pública. Depois de efetivada a atividade, desenvolvida durante um semestre, aplicou-se instrumento para aquilatar a pertinência da atuação dos alunos com essa proposta de trabalho. Os dados levantados permitem afirmar que esta forma de atuação oportunizou uma aprendizagem colaborativa, ativa, interativa, mediada e autorregulada.
\end{abstract}

\section{Palavras-chave}

Tutoria; Ensino; Aprendizagem entre estudantes

\section{Introdução}

Neste início do século XXI, os sistemas educativos buscam se adaptar às novas demandas sociais, as quais exigem transformações nas práticas pedagógicas adotadas pelos educadores. Estas demandas estendem-se também aos estudantes, pois a sociedade contemporânea requer sujeitos com domínio de diferentes habilidades e competências, que os capacitem ao enfrentamento de emergências, quer pessoais quer profissionais. Entre elas, 
destacam-se as exigências advindas das inovações tecnológicas surgidas em diferentes campos da atividade humana, as quais simultaneamente impulsionam mudanças na forma de saber/aprender/fazer/ser.

O relatório elaborado pela Comissão Internacional de Educação (Delors, 1999) evidenciou que a educação se sustentará, na contemporaneidade, sob a égide de pilares em que a construção de saberes e fazeres não mais acontecerá de modo isolado e individualizado, mas com ênfase na convivência e na parceria. A educação tinha como foco, até então, a preparação de sujeitos capazes tanto de posicionarem-se na sociedade, como de fornecerem mão de obra especializada e qualificada às empresas. Tendo como finalidade a transmissão de informações e conhecimentos necessários à realização de tarefas, a educação era pensada como um conjunto de propostas voltadas para a aprendizagem de conteúdos curriculares. Atualmente, no entanto, ela precisa ser pensada através da reflexão sobre o o quê, o para quem e o porquê, considerando diferentes culturas, espaços, identidades individuais e grupais (Grinspun, 2001).

Por ser a aprendizagem um fenômeno interpretativo da realidade, ela implica construção, desconstrução e reconstrução (Demo, 2000). Isto pressupõe a superação do modelo em que o sujeito reproduz fielmente o the é transmitido, não sendo mais aceitável que só o professor ensine e que o aluno apenas absorva passivamente os conteúdos ou que se restrinja a executar somente o que é determinado. A mudança ora empreendida caracteriza-se pela transição do modelo tradicional, próprio de uma sociedade mecanicista, compartimentada, reducionista, na qual prevalecia a objetividade, ou seja, a separação entre o sujeito e o objeto e os sujeitos entre si (Moraes, 2004), para um novo modelo centrado em um sujeito que pensa, faz escolhas, decide, reflete. A nova forma de ação pressupõe controle, consciência, estímulo à criação e à originalidade. Olha-se, portanto, para o ser humano, não apenas como processador de informações ou mero executor de tarefas, mas como sujeito que cria e posiciona-se. As práticas pedagógicas devem, pois, permitir e estimular que os estudantes tornem-se autônomos em sua aprendizagem, regulem e controlem suas cognições, motivações e comportamentos, com o intuito de alcançar objetivos e metas traçadas (Rosário, 2004). 
A grande divisão entre a aprendizagem concebida pela escola tradicional e a configurada pela escola reflexiva decorre das concepções teóricas emergidas na contemporaneidade e de sua aplicação prática no universo escolar. Isso se configurou quando os teóricos Vygotsky (1995) e Piaget (1976) perceberam que os sujeitos exerciam papel ativo no processo de aprendizagem. A compreensão sobre os aprendentes mudou muito e, por consequência, as propostas pedagógicas sofreram alterações. A alternativa que agora se intenta é estimular os sujeitos a pensarem e agirem de forma estratégica e intencional, autorregulando sua aprendizagem. A ação de autorregular a aprendizagem envolve a participação ativa, construtiva, participativa e autônoma dos sujeitos (Veiga Simão, 2004).

A premissa que acompanha o construto da autorregulação da aprendizagem é que o conhecimento se constrói à medida que o sujeito é provocado a desenvolver competências, através de estratégias de aprendizagem, que os capacitam a saber aprender. Não basta, portanto, apenas promover espaços de reflexão e apreensão de conhecimento se as aprendizagens não forem sistematizadas pelo próprio sujeito: "Os alunos têm que querer aplicar esses ensinamentos estratégicos na prática" (Rosário, Veiga Simão, Chaketa, \& Grácio, 2008, p. 118). Compreende-se, pois, que o perfil profissional não se configura mais pelas tarefas ou atividades exercidas isoladamente. Morin (2000) afirma que é necessária a reforma do pensamento humano para responder aos desafios da globalidade, da complexidade da vida cotidiana, no que diz respeito às questões sociais e profissionais. Ele salienta que não basta ter uma cabeça bem cheia, é preciso ter uma cabeça bem feita: "Uma cabeça bem feita significa que, em vez de acumular o saber, é mais importante dispor ao mesmo tempo de: uma aptidão geral para colocar e tratar os problemas e princípios organizadores que permitam ligar os saberes e lhe dar sentido" (Morin, 2000, p. 21). Assim, os professores e as práticas de ensino reconfiguram-se, desafiando os alunos a serem mais conscientes e perspicazes em suas escolhas, na busca de melhores índices de aprendizagem.

Neste contexto, a tutoria associada à autorregulação da aprendizagem estimula a compreensão, oportunizando melhores condições para os sujeitos aprenderem. A ação tutorial promove estratégias de percepção para melhor entendimento do conteúdo trabalhado, estabelecendo relações com outros 
conteúdos aprendidos. O grande desafio da educação hoje é desencadear e implementar ações que promovam os processos de ensino e de aprendizagem. A aprendizagem adquire significado por resultar da interação de um conhecimento anterior com novas experiências, advindas do contexto social e profissional, e da conjugação de variáveis pessoais que estimulam e oportunizam uma forma de agir intencional e estratégica (Veiga Simão, 2005). Nesta perspectiva, buscou-se trabalhar com ênfase no desenvolvimento de competências capazes de (re)orientar e potencializar uma ação autorregulatória, estimulando os envolvidos a pensarem sobre sua aprendizagem, tendo consciência de si mesmos, de suas necessidades e das necessidades do mundo que os rodeia.

Contribuições recentes sobre ação educativa foram apresentadas por Capra (1997), Morin (2000, 2001), Sousa Santos (2000), Tavares e Alarcão (2001), entre outros. Eles investiram em diferentes propostas pedagógicas, no âmbito da docência, das aprendizagens e da avaliação, mostrando aos educadores a necessidade de serem mediadores, isto é, verdadeiros instrumentos de intervenção, promotores do sucesso acadêmico de alunos, de suas práticas, da educação e da instituição (Tavares, 2003). Nesta lógica, o trabalho realizado em parceria entre os alunos ganha força, por contribuir para a aprendizagem. Cabe, pois, aos docentes universitários proporem novas estratégias autorregulatórias, que promovam o desenvolvimento de habilidades e competências, na busca de uma aprendizagem mais efetiva.

Com o objetivo de investigar uma prática pedagógica que contemple estas questões, apresentam-se, neste texto, aspectos teóricos sobre a origem e as diferentes dimensões da tutoria. Na sequência, analisa-se uma intervenção pedagógica com ênfase no trabalho de tutoria realizada entre estudantes do Ensino Superior.

\section{Contextualizando a origem da tutoria}

A palavra 'tutoria' vem do latim tutari e significa pôr em segurança, proteger, defender, guardar, ser protetor - o que justifica seu uso no sentido de assumir, tutelar alguém, cuidar, zelar por uma pessoa ou um grupo (Brutten, 2008). Essas características passaram a conceituar a ação do tutor, ou seja, do indivíduo que é encarregado de cuidar, de tutelar alguém. Ferreira 
(2000, p. 1729) define tutoria como a "função que um indivíduo assume legalmente ao ser encarregado de cuidar, de proteger e defender alguma pessoa". Na escola, o aluno pode ser designado como professor de outros alunos, em formas alternativas de ensino.

No Brasil, a discussão do papel que a tutoria desempenha está bastante atrelada à compreensão de sua utilidade na Educação à Distância. Embora não esteja a ela restrita, é modalidade empregada nas atividades de ensino não presencial: o tutor é o interlocutor à distância, por estar on-line, à disposição do aluno, em determinados horários. Nos países europeus, pela exigência da reforma universitária de Bolonha, que tem como uma de suas metas a alteração dos métodos de ensino e aprendizagem, e pelas pesquisas realizadas sobre estratégias de aprendizagem, especialmente pelos espanhóis Duran e Vidal (2007) e pelos portugueses Veiga Simão e Flores (2008), Baptista, Bessa, \& Tavares (2008), a tutoria, entendida como articuladora das atividades formativas, tornou-se estratégia importante para favorecer o desenvolvimento pessoal e intelectual de todos universitários e para ampliar o sucesso acadêmico.

A tutoria na forma presencial prioriza, segundo Roncelii e Gagno (2008), atendimentos sistemáticos, com o objetivo de orientar a discussão das temáticas e sistematizar conhecimentos teóricos, aproximando alunos e professores, em um trabalho coletivo, no qual tutores e tutelados compartilham saberes, esclarecem dúvidas. Esta modalidade de ensino tem predomínio no atendimento aos alunos e na organização de estratégias pedagógicas regulatórias, que se solidificam ou se harmonizam com a ideia de que todos podem aprender. Essa aprendizagem vai ocorrer na efetiva participação dos alunos; o tutor aprende ao interagir com o tutorando, que também aprende em um trabalho coletivo, promovendo sucesso nas aprendizagens acadêmicas.

A tutoria é considerada, por Roncelii e Gagno (2008), uma modalidade de trabalho que se configura na relação entre colegas, na medida em que um estudante torna-se responsável por outro, objetivando determinados aspectos da aprendizagem. Neste sentido, tutor é aquele que 'cuida' dos aspectos cognoscitivos e 'ajuda' os alunos a conquistarem autonomia na construção de novos conhecimentos. Segundo eles, a tutoria é uma ação responsável por 'conduzir' os educandos à compreensão dos conteúdos trabalhados nas 
disciplinas cujas aulas frequentam. Portanto, esta estratégia de ensino pode ser exercida nas formas presencial e à distância.

A tutoria, especificamente a presencial, realizada em sala de aula entre estudantes, é uma estratégia de ensino e aprendizagem ainda pouco conhecida e utilizada no Brasil, mas "amplamente difundid[a] em âmbito educativo anglo-saxão, no qual é denominado peer tutoring" (Duran \& Vidal, 2007, p. 14). Estes autores destacam que a tutoria pode acontecer "com a criação de duplas de alunos, com (...) um objetivo comum, conhecido e compartilhado (o ensino e a aprendizagem de conteúdos curriculares) que se consegue por meio de um contexto de relação exteriormente planejado" (Duran \& Vidal, 2007, p. 40).

A figura do tutor adquire importância na tarefa de educar, historicamente caracterizada como uma prática "voltada para a formação educativa de qualidade, alimentando sempre esse caráter de formação permanente" (Brutten, 2008, p. 8). No contexto de uma aprendizagem ativa, cognitiva, construtiva, significativa, mediada e autorregulada, a tutoria assume particular importância no ensino universitário, por ser uma proposta que valoriza o desenvolvimento da autonomia, estimula a troca e a parceria no processo de aprender. $\mathrm{O}$ trabalho com a tutoria facilita "o desenvolvimento integral dos estudantes, nas suas dimensões intelectual, afetiva, pessoal e social" (Veiga Simão, Flores, Fernandes, \& Figueira, 2008, p. 77).

\section{Um pouco da história da tutoria}

Brutten (2008) apresenta, em seu artigo A tutoria na educação: suas origens e concepções, uma retomada histórica da ideia de tutoria, desde a mitologia grega até o Renascimento:

- na mitologia greco-latina, o tutor era definido como alguém destinado à proteção divina - Júpiter, Deus protetor dos homens;

- no direito romano, o exercício da tutela aparece caracterizado como zelar por alguém que se encontra fora do pátrio poder, por força da Lei. No direito da família, em Roma, ser tutor significava cuidar, assegurar, dar garantia aos direitos de um menor que ficava sob a responsabilidade de um adulto, na ausência dos pais (Pereira, 1959); 
- na educação romana, os registros indicam que esta prática está associada ao processo de helenização ${ }^{1}$, decorrente da conquista da Grécia pelos romanos. Assim, os gregos que detinham notório saber foram transformados em pedagogos para educar as crianças da nobreza romana (Pereira, 1959);

- na Idade Média, os registros explicam que a tutoria defendia a proteção e a vigilância, com o intuito da formação de cavalheiros, exigida para cultivar a conduta cortês. No final da Idade Média, aparecem os tutores da educação individual, com caráter humanista, promovida pelos mestres livres (ensino particular);

- no período renascentista, "a educação torna-se humanista, com destaque na formação individualizada, personalizada, sob a orientação de Tutores ou Preceptores" (Brutten, 2008, p. 5).

A figura do preceptor particular, centrando a ação dos tutores no atendimento às necessidades infantis, surge com Froebel (1782-1852). Na Inglaterra, no séc. XVIII, tiveram início os trabalhos com monitores, escolhidos entre os alunos mais experientes (Manacorda, 1989), os quais se dedicavam ao atendimento de crianças mais pobres. A eles foi atribuída a denominação 'tutores'. Nas universidades inglesas, essa modalidade de ensino voltou-se para a orientação acadêmica dos estudantes. Na fase atual, na Espanha, a tutoria está sendo implementada em diferentes cursos, principalmente na educação: alunos e professores assumem a função de tutores, sendo também chamados de orientadores, assessores, facilitadores ou coordenadores da aprendizagem (Gordea y Alba, 1988). Na literatura anglo-saxônica, é comum encontrar a expressão peer mentoring, ao se falar em tutoria. Tal prática existe em muitas universidades dos Estados Unidos, nas quais os tutores exercem papel de orientadores dos alunos (Veiga Simão et al., 2008).

No Brasil, na Educação Básica, a experiência de orientação pedagógica/escolar é considerada uma forma de tutoria. Na orientação de trabalhos acadêmicos, de monografias, dissertações e teses, o tutoramento é uma atividade sistemática (Brutten, 2008). No Ensino Superior, existe o Programa de Educação Tutorial (PET), criado pelo Ministério da Educação, pela Lei $n^{\circ} 11.180$, de 23/09/2005, cujo artigo 12 institui bolsas de graduação para apoiar atividades acadêmicas que integram ensino, pesquisa e extensão. Além dessas modalidades, as Instituições de Ensino Superior (IES) que 
optaram pelo PET buscam propiciar aos alunos participantes a realização de atividades extracurriculares que complementem sua formação acadêmica, atendendo também às necessidades do curso de graduação. Os acadêmicos que atuam no PET são orientados por um tutor, denominado professor tutor. Alunos e professores participantes do programa recebem apoio financeiro, de acordo com a Política Nacional de Iniciação Científica (MEC, 2010).

Pansardi, Da Silva, e Egg (2008) salientam que o PET é um programa com quase 30 anos de funcionamento; ele foi criado pela Coordenação de Aperfeiçoamento de Pessoal de Nível Superior (CAPES), em 1979, e denominado 'Programa Especial de Treinamento'. Em 2004, passa a ser identificado como 'Programa de Educação Tutorial' e tem como finalidade contribuir com as instituições comprometidas com a qualificação de profissionais. O PET seleciona candidatos e oferece-Ihes reais condições de aprimoramento e crescimento intelectual. Assim, cada curso, dentro de sua especificidade, executa projetos que levam benefícios à comunidade, promovendo, paralelamente, a formação acadêmica ampla e qualificada dos alunos de graduação envolvidos, direta ou indiretamente, com o Programa.

Realçando a importância da tutoria, a Universidade de Lisboa (Portugal) organizou, em 2008, o XVI Colóquio da Educação, dedicado ao estudo da tutoria como mediação em educação, considerada importante alternativa para fazer frente aos novos desafios educacionais. A tutoria centra sua ação no trabalho interativo entre estudantes e professores, estimulando a aprendizagem contínua e ativa ao longo da vida. Segundo pesquisa divulgada por Veiga Simão e Flores (2008), os programas de tutoria curricular são utilizados, nas universidades de Portugal, com a intenção de responder às necessidades de apoio e de orientação dos alunos universitários. No artigo 'Experiências de tutoria: problemas e desafios', as autoras (idem) descrevem o programa de tutoria desenvolvido pelo Instituto Superior Técnico, em Portugal, que tem como "objetivo proporcionar um acompanhamento personalizado, permanente e formal do percurso escolar do estudante" (p. 5). Cada tutor recebe um crédito por semestre para acompanhar um grupo de 10 a 15 estudantes, em atividades extraclasse.

Os autores espanhóis Duran \& Vidal (2007) destacam que a tutoria assume, no Ensino Superior, particular importância em relação ao modelo acadêmico que prevê a consecução dos objetivos preconizados pela reforma 
de Bolonha. Embora, ao falar em tutoria, se fale quase automaticamente em um ensino mais individualizado, é possível considerar que a tutoria "é uma estratégia de ensino que pode ser utilizada com os mais diversos objetivos" (Brutten, 2008, p. 6). Entre tais objetivos destaca-se o de orientar estudantes ou pessoas da comunidade, individualmente ou em grupo, através de universitários ou de professores. O trabalho é feito tendo presente a necessidade de desenvolvimento de competências acadêmicas ou profissionais. Depreende-se disso que o planejamento das ações da tutoria acontece quando os alunos traçam objetivos e metas e esforçam-se para atingi-los ou quando as instituições de ensino assumem a tutoria como proposta de mediação, para que os estudantes aprendam com mais eficácia.

\section{Metodologia da pesquisa realizada}

Considerando as ideias sobre tutoria já explicitadas, realizou-se uma pesquisa em uma turma de universitários do Curso de Pedagogia, de uma universidade pública, tendo como foco a tutoria entre estudantes, realizada em sala de aula, com o objetivo de trabalhar conteúdos didáticos relacionados à Educação Infantil. Buscou-se avaliar se o ensino tutorial, realizado com 52 estudantes, durante um semestre letivo, estimulou o desenvolvimento cognitivo e a aprendizagem do conteúdo abordado. Levantou-se a hipótese de que a tutoria entre estudantes promoveria a aprendizagem.

Para a realização do trabalho, os alunos foram organizados em duplas, inicialmente por livre escolha. Ao final do semestre, as duplas foram sorteadas, para que os estudantes pudessem avaliar em qual modalidade (espontânea ou sorteio) o trabalho tornou-se mais producente. Nas duplas, propôs-se atividade de tutoria alternada: ora um aluno assumia o papel de tutor, ora outro. Ambos, portanto, ajudavam-se mutuamente na compreensão dos conteúdos ministrados. O trabalho em dupla objetivou ajudar os alunos a superarem dificuldades de aprendizagem relacionadas à compreensão das práticas concernentes à Educação Infantil. Buscou-se também promover parceria, integração e a inserção de todos os alunos no grupo. Solicitou-se autorização, por escrito, para utilização dos dados coletados, firmando-se que a identidade dos participantes seria mantida em sigilo. 


\section{Descrição da prática investigada}

Antecedendo a análise dos dados coletados a partir da intervenção realizada, explicita-se como o trabalho foi desenvolvido. O professor solicitou, como tarefa extraclasse, que os alunos realizassem a leitura de cinco textos para apresentação, em diferentes datas, no decorrer do semestre. No dia preestabelecido, os alunos deveriam levar, por escrito, o 'suco' e a 'teia' do texto marcado para aquele dia. Pretendia-se compartilhar, discutir, compreender os conteúdos, com a leitura individual atrelada ao trabalho coletivo. No dia combinado, durante uma hora, a dupla trabalhou na reescrita do texto, depois socializou esta reescrita com o grande grupo. Apesar de árduo, o trabalho do 'suco' e da 'teia' foi feito pela totalidade dos alunos. Damiani (2008, p. 143) assinala que a elaboração de 'sucos' e 'teias' de textos é apropriadamente usada no Ensino Superior. Tal autora define 'suco' como "uma descrição breve do conteúdo do texto, uma espécie de síntese, cujo nome lhe foi atribuído porque se caracteriza, necessariamente, como algo condensado, como um sumo concentrado de uma fruta". Nele deve constar "em poucas 'gotas' o que a estudante entendeu desse conteúdo". A 'teia' refere-se às relações dialógicas que "o estudante estabeleceu entre o conteúdo do texto lido e os de outros textos, ideias e experiências" (Damiano, 2008, p. 144). Seguindo esta lógica, cabia a um ou outro dos participantes da dupla assumir o papel de tutor, com o objetivo de conduzir a realização da tarefa. Esta função, no entanto, ia se alternando espontaneamente, na medida em que um dos colegas, ao abstrair o sentido do texto, assumia o papel de tutor e propunha diferente posicionamento sobre o que tinha sido escrito ou questionava sobre o que não havia compreendido ao ler o texto.

Os dados coletados na intervenção feita foram submetidos à técnica de análise de conteúdo (Bardin, 1977). Apresenta-se a seguir: a) a análise da prática realizada, com as devidas categorias; b) os indicadores implícitos nas categorias de análise.

\section{Análise da prática realizada}

Os textos contendo o 'suco' e a 'teia' foram discutidos entre a dupla de estudantes e depois apresentados e submetidos à análise crítica do grande grupo. Este avaliava se o 'suco' apresentado estava completo e/ou se tinham 
sido destacadas as ideias principais do texto em estudo. Os universitários faziam comentários, correcções, e novas informações iam sendo inseridas ao texto, modificando a construção anterior. $\mathrm{Na}$ análise do texto da 'teia', repetiuse o mesmo processo: os colegas analisaram a escrita elaborada pelas duplas, complementando-a quando necessário. A reescrita do 'suco' e da 'teia' foi uma conquista gradativa, porque, logo de início, os estudantes verbalizaram que seu texto estava completo, e só depois da análise feita pelos colegas é que perceberam as repetições e a ausência de ideias.

Ficou combinado que somente na aula subsequente à apresentação de 'sucos' e 'teias' os trabalhos seriam recolhidos, a fim de que os estudantes pudessem rever, mais uma vez, o que tinham escrito. Assim, as duplas puderam complementar o 'suco' e a 'teia', inserindo sugestões propostas pelo grande grupo, ampliando a compreensão do texto. O trabalho realizado durante o semestre permitiu debate, troca de ideias, exercício da escrita sobre os textos lidos e aprofundamento teórico, ratificando que, na tutoria, a diversidade constitui-se em "algo positivo que funciona a favor da tarefa docente, tendo como finalidade que cada aluno aprenda com os demais e se sinta responsável tanto pela sua aprendizagem quanto pela de seus companheiros" (Duran \& Vidal, 2007, p. 15).

O relato dos universitários indicou que houve melhora na compreensão dos textos lidos e na escrita dos textos por eles elaborados. Isto demonstra que o grupo entendeu a proposta de trabalho e que, ao realizá-la, a assumiu, avaliando e analisando o que fora escrito e reescrevendo para que ficasse mais completo. Este exercício evidenciou empenho por parte dos acadêmicos e mostrou que eles ampliaram a compreensão do texto lido, perceberam com mais perspicácia as teses do autor, reescreveram as ideias principais com as próprias palavras, organizaram argumentos para explicar o que entenderam sobre o assunto, complementaram sua escrita com a compreensão explicitada pelos demais colegas.

A tutoria, na opinião da maioria dos estudantes, trouxe avanços significativos. No entanto, apresentou também algumas dificuldades. Os dados coletados foram analisados e tabulados em duas grandes categorias: 1) aprovação da tutoria; 2) críticas sobre a tutoria. Em cada uma destas categorias, foram elencadas sub-categorias de análise. 
$\mathrm{Na}$ categoria 'aprovação da tutoria', as sub-categorias de análise foram: conhecimento geral da área de atuação; conhecimento específico da área de atuação; ação didático-pedagógica; aprendizagem significativa; relação de parceria; e ação investigativa - expressas pela maioria dos estudantes envolvidos na proposta de trabalho.

- Conhecimento geral da área de atuação: o trabalho de tutoria tornou possível aos acadêmicos abstraírem conhecimentos a partir do aprofundamento teórico possibilitado pelos textos da disciplina e também pelas reflexões feitas com os colegas em sala de aula. Este fato configura-se como o principal ponto da formação dos saberes educativos e formativos implícitos na prática docente.

- Conhecimento específico da área de atuação: os alunos aprenderam que precisam saber para fazer, o que abrange a compreensão do conhecimento pedagógico e do conhecimento específico do conteúdo de ensino relativo à Educação Infantil. Perceberam também que para ensinar é preciso qualificar-se sistematicamente, sendo que o investimento no estudo torna-se o alicerce da formação continuada e qualificada.

- Ação didático-pedagógica: promoveu a compreensão de que é necessário planejar, executar e avaliar as diferentes estratégias de aprendizagem, para que elas levem à qualificação do ensino e da aprendizagem. A compreensão da teoria estudada oportunizou a superação da insegurança presente tanto na formação inicial como no início da carreira docente. A vivência no grupo, a escrita/reescrita dos textos favoreceram a visão das metas e dos objetivos que precisam ser traçados para o enfrentamento das dificuldades diárias na escola de Educação Infantil. A ação didáticopedagógica voltada à capacidade de saber, conhecer, planejar, executar e avaliar as estratégias de mediação contribuíram para a superação das dificuldades prático-metodológicas sentidas pelos estudantes em processo de formação.

- Aprendizagem significativa: possibilitou aos acadêmicos compreenderem que, para aprender, são requeridos dedicação, aprofundamento de conteúdos, muita leitura. Eles entenderam que não basta tangenciar conteúdos mínimos, pois é preciso refletir 
sobre eles e sobre as diferentes práticas pedagógicas. Ao mesmo tempo em que construíram significados sobre os conteúdos do ensino, os estudantes aprenderam sobre a própria situação didática e sobre as representações de si. Citando Solé (2004, p. 39), "podemos afirmar que, quando aprendemos, aprendemos os conteúdos e também aprendemos que podemos aprender; quando não aprendemos os conteúdos, podemos aprender algo: que não somos capazes de aprender".

- Relação de parceria entre estudantes: mostrou que trabalhar colaborativamente com as diferentes compreensões, expressas por cada aluno, é não só necessário mas também extremamente profícuo. A troca e a parceria permitiram estabelecer e fortalecer o aprofundamento teórico do grupo. As relações contribuíram para o aprendizado individual, favoreceram a compreensão de que o trabalho em equipe faz parte do contexto escolar, evidenciaram que o debate acadêmico amplia a visão teórico-prática.

- Ação investigativa: a proposta de tutoria instigou a imersão na investigação, isto é, fez com que os acadêmicos pesquisassem novas contribuições teóricas e empíricas, que, ao serem apresentadas ao grupo, mobilizaram a organização e o detalhamento de novos projetos educativos com o intuito de serem implementados na Educação Infantil. Os estudantes perceberam que a ação investigativa é uma competência que permite identificar inúmeras situações intervenientes no processo de ensinar e de aprender.

$\mathrm{Na}$ categoria 'críticas sobre a tutoria', os alunos referiram-se a dificuldades encontradas nas seguintes sub-categorias: exigência de leitura e de escrita; dificuldades de ler e compreender o que lê; exigência e comprometimento no trabalho em equipe.

- Exigência de leitura e de escrita: ler o texto com antecedência provocou certa inquietação; alguns estudantes verbalizaram que foi uma tarefa que exigiu mais consciência e controle do que estavam habituados. Consideraram a tarefa árdua, visto estarem acostumados a ouvir do professor alguma explicação sobre o texto a ser lido, de modo que, muitas vezes, a leitura acabava não sendo 
feita. A proposta da tutoria, no entanto, rompeu com esta lógica, porque exigiu leitura e escrita prévias.

- Dificuldades de ler e compreender o que lê: alguns estudantes resistiram a este processo, fazendo o trabalho superficialmente; revelaram-se maus leitores e, consequentemente, maus escritores, dificultando o trabalho da dupla. Tais estudantes disseram que escrever o 'suco' e a 'teia' era extremamente estressante. Neste sentido, Curto, Morillo, e Teixidó (2000, p. 88) dizem que "a escrita em duplas parece ser especialmente adequada para melhorar a aprendizagem e a qualidade do que se escreve". A compreensão desta assertiva foi surgindo no decorrer do trabalho, graças às aprendizagens individuais sistematizadas.

- Exigência e comprometimento no trabalho em equipe: os alunos relataram que trabalhar em duplas foi uma experiência que provocou resistências. Mesmo assim, entenderam que a atuação em equipe privilegia projetos educativos, promove a autenticidade e estimula o fortalecimento da capacidade de compreender o mundo, contribuindo para uma aprendizagem autônoma e autorregulada.

\section{Indicadores implícitos nas categorias de análise}

Os acadêmicos observaram e refletiram sobre o quê e como fizeram a tarefa solicitada. No final do trabalho, através de uma avaliação escrita, os estudantes revelaram terem avançado bastante, especialmente nas aprendizagens realizadas durante o processo. Destacam-se, a seguir, indicadores que fortaleceram as seguintes sub-categorias de análise: conhecimento específico da área de atuação; ação didático-pedagógica; aprendizagem significativa; relação de parceria; ação investigativa.

Posso dizer que dos pontos fortes deste trabalho o melhor foi ter trabalhado em duplas, pois nos ajudou a formar um raciocínio, trocar experiências, aprender a lidar com outro ponto de vista (E1).

O trabalho de tutoria foi um sucesso, oportunizou aprofundamento teórico, uma ótima interação entre as duplas. Através dele, conseguimos ampliar o conhecimento específico da área de atuação, enriquecendo nossa aprendizagem. Aprendemos a lidar com as situações inesperadas (E20).

O trabalho foi relevante por ser uma experiência nova e diferente, que oportunizou a investigação e a construção de novos conhecimento. Fez-me entender melhor o que estou estudando (E32). 
O mais importante é que todos nós tivemos oportunidade de interagir com um colega. A interação, a troca de ideias foram fundamentais para fazer a relação com os conhecimentos e os conteúdos trabalhados. Essa parceria me fez aprender (E3).

$\mathrm{Na}$ categoria 'críticas sobre a tutoria', foram encontrados pontos de fragilidade na exigência da leitura e da escrita, bem como na compreensão do que cada um lê. Na formação acadêmica dos universitários, percebeu-se a existência de grande defasagem nas competências desejáveis para ler e escrever. Vê-se, portanto, a urgência de continuar a implementar estratégias que possam reverter as carências apresentadas em relação à leitura e à escrita dos estudantes. Outra dificuldade marcante manifestada foi quanto à competência de saber partilhar, tendo comprometimento com o trabalho de equipe. Isso se evidenciou nas duplas de alunos que tiveram dificuldades oriundas quer do relacionamento mútuo, quer da falta de comprometimento com a leitura e a escrita dos textos. A heterogeneidade é importante na relação de aprender, pois, através do diálogo, podem surgir diferentes hipóteses que venham a contribuir na construção de significados (Santos, 2001). Há diferenças no processo de aprendizagem dos alunos; no entanto, cada um pode investir e cooperar com suas ideias, beneficiando a aprendizagem de todos.

Apresentam-se, abaixo, alguns indicadores das seguintes subcategorias: exigência de leitura e de escrita; dificuldades de ler e compreender o que lê; exigência e comprometimento no trabalho em equipe.

As aulas tornaram-se repetitivas com leituras superficiais, penso que seria melhor a leitura de menos textos e mais discussão sobre o texto proposto para o trabalho (E20).

Reconheço que, quando se trata de socializar as sínteses no grupo, nem todos assumem igualmente, o que torna o processo muito desgastante para alguns (E11).

Estes depoimentos não desarticulam o trabalho feito; porém, confirmam a necessidade de se investir no trabalho de tutoria, melhorando as práticas promotoras de aprendizagens significativas. Na sistematização dos depoimentos, destacaram-se algumas falas que evidenciam: necessidade de mais tempo para leitura dos textos; importância de agregar projeções de filmes e documentários que enriqueçam a análise das práticas a serem realizadas nas escolas infantis; vantagem da presença de professores 
educadores da escola infantil, para com eles conhecerem e debaterem suas experiências e vivências diárias. A análise geral do trabalho revelou que esta prática foi produtiva e evidenciou que é requerido ao educador o comprometimento com as estratégias autorregulatórias, uma vez que elas estimulam o aluno a atuar autonomamente, propiciando-lhe autorreflexão e autorregulação das ações para aprender.

\section{Efeitos da atividade de tutoria sobre a aprendizagem dos conteúdos}

Os dados coletados mostraram que a ação tutorial estimulou o desempenho cognitivo, conforme destacado por todos os participantes. Atribui-se a obtenção deste resultado tanto ao envolvimento e ao desempenho das competências individuais na preparação da leitura e da escrita do 'suco' e da 'teia', quanto à articulação das ideias efetivada pelos estudantes. A proposta de atuarem em parceria causou estranhamento ao grupo, por estarem os participantes acostumados a trabalhar, predominantemente, de modo individual e competitivo, bem distante das metas e dos objetivos coletivos propostos neste trabalho. Os alunos, mesmo assim, investiram no trabalho e demonstraram dedicação, interesse, disponibilidade na realização das tarefas propostas. Eles expressaram ter sido necessário refletir mais sobre o que já sabiam para explicar suas ideias ao colega. As reflexões feitas pelos participantes podem ser melhor entendidas pela leitura de alguns excertos:

Meu desempenho foi bom. Poderia ser melhor, se tivesse lido os textos mais de uma vez. No entanto, trabalhar na dupla ajudou-me a melhorar a escrita. Pude notar grande progresso na minha interpretação dos textos (E43).

Destaco que, na aula, quando a professora fazia as duplas lerem o que tinham escrito, explicava algo ou questionava sobre o texto, isto fazia com que todos refletissem, compreendendo o que tinham escrito (E35).

Minha aprendizagem foi ampliada, aprimorada exatamente através das trocas pelas quais passamos (E24).

Estes indicadores mostram também questões relativas à autoestima e à autoimagem, que sempre estão vinculadas à aprendizagem. Eis um fato marcante no depoimento de um dos estudantes: 
Sempre tive dificuldade de aprender, fui rotulado pelos colegas e professores como alguém que tem dificuldade. Agora vejo que aprendo com mais facilidade investindo na leitura, na escrita, pedindo ajuda para o colega tutor. Acho que passei a acreditar em mim. Aprendi muito com este trabalho. Posso dizer que, em alguns momentos, também fui tutor (E17).

Percebe-se que estão implícitos, na aprendizagem, tanto fatores cognitivos quanto afetivo-relacionais, os quais podem ser melhor aproveitados no trabalho em duplas, pelo fortalecimento trazido pela ajuda recíproca. A tutoria realizada entre colegas da mesma turma permitiu a construção simultânea de estratégias de aprendizagem, ou seja, um ajudou o outro a aprender e um aprendeu com o outro. Conforme salientam Duran \& Vidal (2007), o tutor torna-se um mediador da aprendizagem e, ao fazê-lo, também aprende e supera suas lacunas. Excertos de alguns depoimentos ilustram tal assertiva: "ao ajudar o colega, me dei conta de que aprendi com ele"; "sintome gratificado, estou aprendendo e me preparando para os desafios que deverei enfrentar no futuro como professor"; "foi difícil e exigente o trabalho realizado, mas posso dizer que aprendi muito com ele"; "este trabalho preparou-me para ser uma professora qualificada".

As manifestações de alguns alunos indicam que a tutoria oportunizou: aumento da responsabilidade e do controle; melhor realização das tarefas solicitadas; organização e sistematização de estratégias fortalecedoras da aprendizagem; crença de que é possível aprender, sendo, para tanto, preciso investir no estudo e na interação, os quais fortalecem a compreensão e auxiliam a construção do conhecimento. Aqui se compreende a dimensão da interação social: o trabalho conjunto alavanca a aprendizagem, isto é, possibilita ultrapassar o estágio de regulação externa assistida para alcançar a autorregulação interna. Vigotski (1995) definiu este movimento como a lei da dupla formação das funções psicológicas superiores: as funções de desenvolvimento aparecem primeiro no interpsíquico ou social, para depois autorregular o intrapsíquico ou individual.

\section{Considerações finais}

A tutoria estimulou a autorregulação das aprendizagens individuais, a qual foi oportunizada pela realização das atividades propostas nas diversas etapas de desenvolvimento do trabalho. Os diferentes níveis de detalhamento 
utilizados para planejar e para preparar o 'suco' e a 'teia', construídos com argumentos pessoais entre os estudantes, provocaram "nova escrita", isto é, nova compreensão da leitura feita. Este trabalho levou os acadêmicos a se envolverem e a assumirem a tarefa com consciência e autocontrole.

Pensar sobre tutoria pressupõe ativar a ação regulatória da aprendizagem em relação à atuação do professor, que visa criar, implementar e ajustar as estratégias de ensino necessárias à progressão das aprendizagens do aluno, seja acompanhando o desenvolvimento das etapas pelas quais ele passa, seja planejando, executando ou avaliando as estratégias regulatórias por ele empregadas. O planejamento detalhado e a "reflexão sistemática de e sobre o que acontece na aula", bem como "a atuação diversificada e flexível em função dos objetivos previstos no planejamento" (Coll \& Solé, 1989, p. 123), são ações imprescindíveis para que o ensino promova a aprendizagem. O professor, ao implementar sua prática pedagógica, ajusta progressivamente sua atuação em função dos conhecimentos e da experiência profissional que possui, levando em conta que a estratégia de ensino utilizada poderá promover ou não a aprendizagem do aluno.

A pesquisa realizada mostrou que o professor, ao escolher estratégias regulatórias, confronta-se com a necessidade de planejar e organizar não só atividades que envolvam a compreensão dos conteúdos (interpretação, exemplificação, reflexão, análise crítica), mas também estratégias que levem o aluno a desenvolver competências cognitivas (memória, elaboração, reconhecimento, identificação, aplicação, entre outras). Todas essas ações são importantes para autorregular a aprendizagem do estudante. Com a realização deste tipo de prática, os alunos: compreenderam melhor os temas tratados; perceberam a importância da atuação como tutores; constataram que a aprendizagem entre estudantes pode ser resultante de uma postura reflexiva; superaram problemas, bloqueios, dificuldades internalizadas que limitavam sua capacidade de aprender.

O trabalho desenvolvido mostrou que a tutoria é uma estratégia de ensino que permite ao aluno avançar em sua aprendizagem, aproximando quem ensina e quem aprende. Os estudantes expressaram que houve aprendizagem significativa, desencadeada pelo desenvolvimento inter e intrapessoal, ativado por objetivos compartilhados, que se alternavam, se 
(re)configuravam, conforme as necessidades e estratégias propostas. Atento e disponível, o professor acompanhou todo o processo, garantindo condições contextuais que viabilizaram a aprendizagem. A tutoria desencadeou um processo de construção autônoma, conquistada para si e para o grupo. Os alunos passaram a conviver com a pluralidade de expectativas, demonstrando grande capacidade em administrar conflitos surgidos nas e das relações interpessoais. A aprendizagem tornou-se uma construção social, ou seja, "não só o professor ensinou e produziu pensamento crítico, mas os colegas, ao trabalhar juntos, ao discutir pontos de vista, ensinaram muito" (Curto, Morillo, \& Teixidó, 2000, p. 87). Ficou evidenciado que os acadêmicos acreditam em propostas de trabalho que exijam seu envolvimento e mostraram ter, simultaneamente, "aprendido e ensinado". A ajuda mútua tornou-se importante no desenvolvimento do processo e, para realizá-la, cada participante viu-se compelido a estudar e a se preparar para os encontros.

A tutoria leva a pensar sobre a necessária mudança de concepção em relação à prática tradicional, de modo a romper a lógica do professor como único depositário do saber e a transmissão linear de conhecimentos. Tal modalidade de trabalho, utilizada em uma perspectiva pedagógica, ultrapassa o ensino programado, estimula o compartilhamento de conhecimentos, conceitos, informações, ajuda os estudantes a melhor aprenderem. Não sendo um ensino fácil, como inadvertidamente se pode pensar, é uma prática que exige acompanhamento, cuidado na formação e muito empenho dos docentes que buscam efetivar este trabalho. No Ensino Superior, assumir esta proposta pedagógica pode significar um grande avanço rumo às transformações pedagógicas requeridas pelas demandas sociais deste início de século.

\section{Notas}

1 Significa dedicar-se ao estudo do idioma e/ou da civilização (Ferreira, 2000, p. 885).

\section{Referências}

Baptista, A. V., Bessa, J., \& Tavares, J. (2008). Os objetivos e a reforma de Bolonha: A tutoria enquanto estratégia para o Ensino Superior. In Atas do XVI Colóquio AFIRSE/AIPELF - "Tutoria e mediação em educação: Novos desafios à investigação educacional". Lisboa: Universidade de Lisboa. 
Bardin, L. (1977). Análise de conteúdo. Lisboa: Ed. 70.

Brutten, E. (2008). A tutoria na educação: Suas origens e concepções. In Atas do XVI Colóquio AFIRSE/AIPELF - "Tutoria e mediação em educação: Novos desafios à investigação educacional". Lisboa: Universidade de Lisboa.

Capra, F. (1997). A teia da vida. São Paulo: Cultrix.

Coll, C., \& Solé, I. (1989). Aprendizaje significativo y ayuda pedagógica. Cuadernos de Psicología, 168, 16-20.

Curto, L. M., Morillo, M., \& Teixidó, M. M. (2000). Escrever e ler: Como as crianças aprendem e como o professor pode ensiná-las a escrever e ler (vol 1). Porto Alegre: Artmed.

Damiani, M. F. (2008). Trabalhando com textos no Ensino Superior. Revista Portuguesa de Educação, 21(2), 139-159.

Delors, J. (1999). Educação: Um tesouro a descobrir. São Paulo: Cortez.

Demo, P. (2000). Conhecer \& aprender: Sabedoria dos limites e desafios. Porto Alegre: Artes Médicas.

Duran, D., \& Vidal, V. (2007). Tutoria: Aprendizagem entre iguais. Porto Alegre: Artmed.

Ferreira, A. B. H. (2000). Novo Dicionário Aurélio da Língua Portuguesa. Rio de Janeiro: Ed. Nova Fronteira.

Gordea y Alba, H. R. (1988). Una propuesta de educación personalizada. Cuadernos de Pedagogía, 158, 26-27.

Grinspun, M. P. (Org). (2001). A orientação educacional: Conflito de paradigmas e alternativas para a escola. São Paulo: Cortez.

Manacorda, M. A. (1989). História da Educação: Da antiguidade aos nossos dias. São Paulo: Cortez.

Moraes, M. C. (2004). Pensamento eco-sistêmico: Educação, aprendizagem e cidadania no século XXI. Petrópolis, RJ: Vozes.

Morin, E. (2000). A cabeça bem feita: Repensar a reforma e reformar o pensamento. Rio de Janeiro: Bertrand do Brasil.

Morin, E. (2001). Ciência com consciência. Rio de Janeiro: Bertrand Brasil.

Pansardi, M. V., Da Silva, S. R., \& Egg, R. F. R. (2008). Programa de educação tutorial e ética na formação do acadêmico de Direito: A habilitação para a mediação de conflitos. In Atas do XVI Colóquio AFIRSE/AIPELF - "Tutoria e mediação em educação: Novos desafios à investigação educacional". Lisboa: Universidade de Lisboa.

Pereira, V. S. (1959). Direito de família (2a ed.). Rio de Janeiro: Freitas Bastos.

Piaget, J. (1976). Para onde vai a educação? Rio de Janeiro: José Olympio.

Roncelii, V., \& Gagno, R. R. (2008). Tutoria. O XVI Colóquio - Tutoria e mediação em educação: Novos desafios à investigação. In Atas do XVI Colóquio AFIRSE/AIPELF - "Tutoria e mediação em educação: Novos desafios à investigação educacional". Lisboa: Universidade de Lisboa.

Rosário, P., Veiga Simão, A. M., Chaketa, E., \& Grácio, L. (2008). Auto-regular o aprender que espreita nas salas de aula. In M. H. M. B. Abrahão (Org.), 
Professores e alunos: Aprendizagens significativas em comunidades de prática educativa (pp. 115-132). Porto Alegre: EDIPUCRS.

Santos, B. S. (2001). Vygotsky e a teoria histórico-cultural. In J. La Rosa (Org.), Psicologia e educação: O significado de aprender (4a ed.). Porto Alegre: EDIPUCRS.

Solé, I. (2004). Disponibilidade para a aprendizagem e sentido da aprendizagem. In C. Coll, E. Martín, T. Mauri, M. Miras, \& Onrubia, J., O construtivismo na sala de aula (pp. 30-54). São Paulo: Ática.

Sousa Santos, B. (2000). A crítica da razão indolente: Contra o desperdício da experiência (vol. 1). São Paulo: Cortez.

Tavares, J. (2003). Formação e inovação no Ensino Superior. Porto: Porto Editora.

Tavares, J., \& Alarcão, I. (2001). Paradigmas de formação e investigação no Ensino Superior para o terceiro milénio. In I. Alarcão (Org.), Escola reflexiva e nova racionalidade (pp. 94-114). Porto Alegre: Artmed.

Veiga Simão, A. M. (2004). O conhecimento estratégico e a auto-regulação da aprendizagem. Implicações em contexto escolar. In A. Lopes da Silva, A. M. Duarte, I. Sá \& A. M. Veiga Simão, Aprendizagem auto-regulada pelo estudante: Perspectivas psicológicas e educacionais (pp. 77-87). Porto: Porto Editora.

Veiga Simão, A. M. (2005). Reforçar o valor regulador, formativo e formador da avaliação das aprendizagens. Revista de Estudos Curriculares, 3(2), 265-289.

Veiga Simão, A. M., \& Flores, M. A. (2008). Experiências de tutoria: Problemas e desafios. In Atas do XVI Colóquio AFIRSE/AIPELF — "Tutoria e mediação em educação: Novos desafios à investigação educacional". Lisboa: Universidade de Lisboa.

Veiga Simão, A. M., Flores, M. A., Fernandes, S., \& Figueira, C. (2008, set/dez). Tutoria no Ensino Superior: Concepções e práticas. Sísifo - Revista de Ciências da Educação, 7, 75-88.

Vygotsky, L. S. (1995). Pensamento e linguagem. São Paulo: Martins Fontes.

\section{Legislação}

Lei $n^{\circ}$ 4.024. Brasil, Ministro da Educação, Conselho Federal de Educação. Disponível em http://www.planalto.gov.br/ccivl_03/Leis/>4024.htm (acesso em 10 de junho de 2009).

Lei $n^{\circ}$ 5.540. Brasil, Ministro da Educação, Conselho Federal de Educação. Disponível em http://www.planalto.gov.br/ccivl_03/Leis/>5540.htm (acesso em 10 de junho de 2009).

Lei $n^{\circ}$ 9.394. Brasil, Ministro da Educação, Conselho Federal de Educação. Disponível em http://www.planalto.gov.br/ccivl_03/Leis/>9394.htm (acesso em 10 de junho de 2009).

Lei $n^{\circ} 11.180$ (Programa de Educação Tutorial). Brasil, Ministério da Educação. Disponível em http://www.planalto.gov.br/ccivil_03/_ Ato2004-2006/2005/ Lei/L11.180.htm (acesso em 25 de junho de 2010). 
Portaria MEC $n^{\circ}$ 591, de 18 de junho de 2009. Brasil, Ministro da Educação, Conselho Federal de Educação. Disponível em: http://www.semesp.org.br (acesso em 20 de junho de 2010). 


\title{
TUTORING AMONG STUDENTS: A WORK PROPOSAL WHICH PRIORIZES LEARNING
}

\begin{abstract}
This article aims at analyzing tutoring, a teaching style used to enhance collaborative learning, performed through the collaboration among students. The historical development of conceptual aspects was explored and the study of tutoring on current days was established as the point of reference. Based on such theoretical support, a work of tutoring among peers was conducted with Pedagogy students of a public university. The activity was evaluated by means of a tool aiming at determining the importance of this strategy for students' performance. The analysis of the results highlighted that the work was productive. The collected data confirmed that this teaching style provided collaborative, active, interactive, mediated and self-regulated learning.
\end{abstract}

Keywords

Tutoring; Teaching; Learning among students

\section{TUTELLE ENTRE ÉTUDIANTS: UNE PROPOSITION DE TRAVAIL QUI MET EN VALEUR L'APPRENTISSAGE}

\section{Résumé}

La raison de cet article est de réfléchir sur la tutelle, entendue comme une modalité d'enseignement, utilisée pour renforcer l'apprentissage collaboratif, réalisé en association entre élèves. On a exploité, d'un point de vue historique, le développement des aspects conceptuels et on a établi l'étude de la tutelle dans l'actualité comme point de référence. Avec ce support théorique, a été réalisé un travail de tutelle entre pairs avec des élèves de Pedagogie d'une université publique. Après la réalisation de l'activité développée pendant un semestre, on a évalué la pertinence de l'actuation des élèves dans cette modalité d'enseignement. L'analyse des réponses a démontré que le travail a 
240| Lourdes Maria Bragagnolo Frison

été productif. Les données relevées permettent affirmer que cette modalité d'enseignement a donné lieu à un apprentissage collaboratif, actif, interactif, partagé et autorégulé.

Mots-clé

Tutelle; Enseignement; Apprentissage chez les élèves

Recebido em Janeiro/2011

Aceite para publicação em Janeiro/2012

Toda a correspondência relativa a este artigo deve ser enviada para: Lourdes Maria Bragagnolo Frison, Rua Engenheiro Rodolfo Ahrons, 285, CEP 91530.320, Intercap, Porto Alegre, Brasil. E-mail: Ifrison@terra.com.br 